\title{
Sperm abnormalities: Adverse effects of thyroid dysfunction
}

\author{
Hassan Niroomand ${ }^{1 \text { \#*}^{*}}$, Sima Binaafar ${ }^{1 \#^{*}}$, Moein Nasiri ${ }^{1}$, Nasrin Mansournia ${ }^{1}$, Atoosa Bagheri \\ Behzad $^{2}$
}

1. Trauma Research Center, AJA University of Medical Sciences, Tehran, Iran

2. Department of Gynecology, Moheb Yas Hospital, Tehran University of Medical Sciences, Tehran, Iran

${ }^{\#}$ These authors contributed equally to this work.

*Corresponding authors:Tel: +989127160698 Fax: +98 2188337932

Address: Trauma Research Center, AJA University of Medical Sciences, Etemadzadeh St. Fatemi Ave. Tehran, Iran

E-mail: Hassanniroomand@ajaums.ac.ir

Received; 2017/10/31 revised; 2017/11/19 accepted; 2017/12/11

\begin{abstract}
Introduction: Despite the importance of thyroid hormones in reproduction, there are only a few studies that focus on male infertility. The objective of this study was to evaluate semen parameters in patients with hypothyroidism or hyperthyroidism.

Materials and methods: Totally, 28 patients with thyroid disorders were evaluated for the semen parameters. Serum TSH and T4 concentrations were measured by ELISA. Complete semen analyses were performed based on WHO.

Results: Pathozoospermia was seen in $32.14 \%$ of our patients. Two hyperthyroid patients and seven hypothyroid patients suffered sperm defects. None of pathozoospermia patients showed an alone sperm defects. Sperm multiple anomalies were our main findings.

Conclusion: It seems that sperm characterizes strongly were affected. Although, we have a limited sample size, but sperm multiple abnormalities made our interest findings.
\end{abstract}

Keywords: Infertility, Semen, Sperm abnormality, Hypothyroidism, Hyperthyroidism

\section{Introduction}

Fertility and childbearing may be one of the desired goals in the couples' life. Unfortunately, approximately 50 to 80 million of people suffer from infertility in worldwide (1-3). Male factor infertility is considered responsible for $30 \%$ of these cases. However, in approximately $15 \%$ of cases, the etiology remains unclear (4). This complex procedure is influenced by varying factors such as hormones. It is now wellestablished that endocrine system has an important physiological role in maintaining and regulation of sexual development and reproductive function (5-7).
There are many studies that target thyroid hormones level variations in infertile couples, commonly female partner. The objective of this study was to compare semen parameters in hypo/hyper thyroid patients without any infertility complaint. Similar study, to the best of our knowledge, has not published from Iran previously.

\section{Material and methods}

Subject: This single center study was approved by the Research committees of AJA University of Medical Sciences in Tehran, Iran (code: 85/90/400) and

Copyright (C) 2018 Journal of Basic Research in Medical Science. This is an open access article distributed under the terms of the Creative Commons Attribution 4.0 International License (https://creativecommons.org/licenses/by/4.0/) which permits copy and redistribute the material, in any medium or format, provided the original work is properly cited. 
informed consent was obtained from all patients. In a during 20 months, those patients, who had been untreated for their thyroid disease, were introduced to the research team by thyroid endocrinology clinic, Emam Reza Hospital, Tehran, Iran. Subjects were excluded if they were /are taking medications or any drug known to potentially interfere with thyroid function or semen characteristics, also had experienced prior vasectomy and cryptorchidism.

Serum assay: Serum TSH and T4 concentrations were measured by ELISA (BioVendor, Heidelberg, Germany). This hormone assay was performed according to the DIAPLUS kit (Toronto, Canada) protocol. The reference ranges of TSH and T4 were $0.39-5.95 \mu \mathrm{g} / \mathrm{dl}$ and $4.4-10.8 \mu \mathrm{g} / \mathrm{dl}$, respectively. Experimental bias was diminished by using a double-blind procedure.

Semen analysis: According to WHO guidelines of 2010, semen samples were collected by masturbation after a 4 day sexual abstinence (8). Following liquefaction for a period of 15 to 30 minutes at room temperature, complete semen analyses were performed. As soon as possible after liquefaction, each sample's motility was evaluated at room temperature with a heated microscope stage that was standardized for our laboratory. Sperm motility was classified as follows: Progressive (class A+B), Non-progressive (class C) and Immotile (class D). The Sperm count assessment was performed with usual manner wet preparation. Using haemocytometer chamber, at least 200 spermatozoa were counted. Concentration in spermatozoa per $\mathrm{ml}$ was calculated. Sperm morphology was evaluated using the Diff-Quick staining method. Briefly, two slides were prepared from each fresh semen sample. After air-drying, fixing and staining, the slides were examined with bright field optics at $\times 1000$ magnification with oil immersion. In this assessment approximately 200 spermatozoa were counted in five squares.

\section{Statistical analysis}

All patients were divided into 2 subgroups according to laboratory hallmarks: hypothyroids and hyperthyroid. Then statistical analyses were carried out using SPSS (v. 15.0) and a value of $\mathrm{P}<0.05$ was considered significant. Continuous variables were summarized as mean and standard deviation and categorical variables as absolute and relative frequencies.

\section{Results}

The participants included 28 individuals ranging in age from 24 to 38 years (mean \pm SD: $29.5 \pm 3.8)$. A total of $6(21.42 \%)$ of 28 patients had considered as hyperthyroidism, which was identified in serum levels of TSH and T4. The average serum levels of TSH and T4 were found $0.8 \pm 0.06 \mu \mathrm{g} / \mathrm{dl}$ and $14.1 \pm 1.5 \mu \mathrm{g} / \mathrm{dl}$ (mean $\pm \mathrm{SD}$ ), respectively. Our results also showed that other participants $(n=22)$ may be in place Hypothyroidism for their TSH and T4 serum levels (mean \pm SD: $9.6 \pm 2.3 \mu \mathrm{g} / \mathrm{dl}$ and $3.4 \pm 0.8 \mu \mathrm{g} / \mathrm{dl}$, respectively).

Normozoospermia was observed in $68.75 \%$ $(n=19)$ of our patients (four in the Hyperthyroidism group vs. fifteen in Hypothyroidism group). Also, pathozoospermia was seen in $32.14 \%$ $(n=9)$ of our participants (Two in the hyperthyroidism group vs. seven in hypothyroidism group).

Five patients in this study suffered from asthenospermia; 1 patients of hyperthyroidism group and 4 patients of hypothyroidism group. No significant difference was observed among groups $(\mathrm{P}=$ 0.571). Our results showed that six patients have morphologically abnormal sperm cells (one in the Hyperthyroidism group vs. five in Hypothyroidism group). There was no significant difference in sperm morphology $(\mathrm{P}=0.657)$ between two groups. Also, no significant difference $(\mathrm{P}=0.515)$ was also seen to exist between total sperm count in both groups $(18.5 \pm 3.9 \times 106$ per $\mathrm{ml}$ in Hyperthyroidism group vs. $20.8 \pm 4.2 \times 106$ per $\mathrm{ml}$ in Hypothyroidism group). 


\section{Discussion}

The interesting finding of the present study is teratospermia. Hyperthyroidism group showed $16.7 \%$ teratospermia and hypothyroid patients demonstrated totally $22.7 \%$ teratospermia. Based on Karras and Pontikides review article, there is a study that reports sperm morphology defects in non-euthyroidism men: De La Balze et al. (5). We observed teratospermia not only in hypothyroids group, but also in hyperthyroid ones. Recently Krassas et al. showed morphology was affected at significant levels in hypothyroid patients (9). Several studies support an association between thyroid hormones and Sertoli cells functions. These studies have demonstrated that thyroid hormones receptors exist in proliferating Sertoli cells. At this point Sertoli cells are introduced as a major target for thyroid hormone. Their effects are probably mediated through the duration of Sertoli cell division and involved in the maturational changes (10). Comparison of studies: Sperm motility is probably a main change in hyperthyroid patients.

Abalovich et al. found that 18 patients $(\mathrm{n}=21,85.7 \%)$ had a motility problem (astenospermia). The same result was obtained by Krassas et al. In their study all patients $(n=23)$ showed astenospermia without any other sperm defects (7). But our results were different. We observed astenospermia associated with teratospemia with one of hyperthyroid patients. In hypothyroid group five patients $(22.7 \%)$ indicated astenospermia that in comparison with Wortsman et al. is much lower. Wortsman et al. found astenospermia in $87.5 \%$ of their hypothyroid patients $(n=8)$ that was associated with oligoteratospermia. A remarkable point in their study could be age. Age could be a remarkable point in these studies. The participants age ranged varied from 17 to 77 years: De La Balzed et al. (17-59) y; Wortsman et al. (37-77) y and present study (24-38) y. This viewpoint is consistent with studies which indicated a significant age- dependent reduction in sperm quality (1113). Although there are few studies that investigated thyroid hormones alterations in the male reproductive system and semen quality, but animal models helped well establish the testicular changes' mechanism. In Wistar rat have been demonstrated that hypothyroidism reduces seminiferous tubules and lumen diameters significantly (14). Also, other studies indicated that Sertoli cell differentiation postponed in hypothyroid rats and these rats showed a prolongation of Sertoli cell proliferation time. It is notable that transient hypothyroidism associated with less damage to the testes (15). Furthermore, sperm count deficiency was emerged as a common defect in our groups. In hypothyroid group, oligospermia was observed in seven patients that was associated with astenospermia and teratospermia and teratoastenospermia. Only two patients of hyperthyroids group showed pathozoospermia in the present study that was not their single sperm defects. This finding is almost near to Clyde et al. (1976) and Kidd et al. (1979) reports in hyperthyroid man, 3 and 5 patients respectively. But there is a main difference; we observed oligospermia was associated with other sperm defects and was not seen as an alone defects in our patients. Moreover, multiple abnormalities made our main finding in this study. Although there are few published studies that report semen analysis in hypo/hyper thyroid patients, but there is no study that report multiple anomalies. In our study, none of hypothyroid affected men demonstrated only a single defect $((n=2: O+T),(n=3$ : $\mathrm{O}+\mathrm{A})$, and $(\mathrm{n}=2: \mathrm{O}+\mathrm{A}+\mathrm{T}))$. And we observed no alone form of pathozoospermia in hyperthyroid affected men $((n=1: O+T),(n=1: A+O))$. It seems there is not same published report from Iranian population, therefore it plays a role as a pilot study. Our study lacked a control population and included a limited 
number of patients in a different age range that make it difficult to draw definitive conclusion. This said, we need to perform further studies on larger appropriate case and control Iranian populations to confirm these observations.

\section{Conclusion}

Scientific investigations support the impact of thyroid hormones on reproductive. These findings demonstrated that thyroid hormones' dysfunction associated with

\section{References}

1. Akhondi MM, Dadkhah A, Bagherpour A, Ardakani ZB, Kamali K, Binaafar S, Kosari H, Ghorbani B. Study of body image in fertile and infertile men. $\mathrm{J}$ Reprod Infertil. 2011;12(4):295.

2. Inhorn MC. Right to assisted reproductive technology: overcoming infertility in low-resource countries. Int J Gynaecol Obstet. 2009; 106(2):172-4.

3. Akhondi MM, Binaafar S, Ardakani ZB, Kamali K, Kosari H, Ghorbani B. Aspects of psychosocial development in infertile versus fertile men. J Reprod Infertil. 2013; 14(2):90.

4. Poppe K, Glinoer D, Tournaye H, Maniewski U, Haentjens P, Velkeniers B. Is systematic screening for thyroid disorders indicated in subfertile men? Eur J Endocrinol. 2006; 154(3):363-6.

5. Krassas GE, Pontikides N, Deligianni V, Miras K. A prospective controlled study of the impact of hyperthyroidism on reproductive function in males. $\mathrm{J}$ Clin Endocrinol Metab. 2002; 87(8):3667-71.

6. Krassas GE, Perros P. Thyroid disease and male reproductive function. $\mathrm{J}$ Endocrinol Invest. 2003; 26(4):372-80.

7. Krassas GE, Pontikides N. Male reproductive function in relation with thyroid alterations. Best Pract Res Clin Endocrinol Metab. 2004;18(2):183-95.

8. World Health Organization. WHO laboratory manual for the examination sperm defects. It seems that these effects are strongly dependent upon the timing of onset and severity. Therefore, more precision is suggested in work up assessment in the clinic.

\section{Acknowledgement}

We would like to thank all of the individuals who kindly accepted to participate in this study. We are also thankful to Dr. Masoudi for his best revision.

and processing of human semen 2000.

9. Poppe K, Velkeniers B, Glinoer D. The role of thyroid autoimmunity in fertility and pregnancy. Nature Reviews. Endocrinology. 2008; 4(7):394.

10. Wagner MS, Wajner SM, Maia AL. The role of thyroid hormone in testicular development and function. $\mathbf{J}$ Endocrinol. 2008 ;199: 351-65.

11. Kidd SA, Eskenazi B, Wyrobek AJ. Effects of male age on semen quality and fertility: a review of the literature. Fertil Steril. 2001; 28; 75(2):237-48.

12. Eskenazi B, Wyrobek AJ, Sloter E, Kidd SA, Moore L, Young S, Moore D. The association of age and semen quality in healthy men. Hum. Reprod.. 2003; 18(2):447-54.

13. Johnson SL, Dunleavy J, Gemmell NJ, Nakagawa S. Consistent age-dependent declines in human semen quality: a systematic review and meta-analysis. Ageing Res Rev. 2015; 31(19):22-33.

14. Krassas GE, Papadopoulou F, Tziomalos K, Zeginiadou T, Pontikides N. Hypothyroidism Has an Adverse Effect on Human Spermatogenesis: A Prospective, Controlled Study. Thyroid. 2008;18(12): 1255-9.

15. Krassas GE, Poppe K, Glinoer D. Thyroid Function and Human Reproductive Health. Endocr Rev. 2010;31(5): 702-55. 